\title{
Long term quality of life in conservatively treated gastric lymphoma patients versus gastrectomized patients and gastritis patients
}

\author{
Jesse Lachter ${ }^{* *}$, Ron Shahory², Nicole Molin ${ }^{3}$ and Yoram Kluger ${ }^{4}$ \\ ${ }^{*}$ Correspondence: ramila@netvision.net.il \\ 'Gastroenterologist in Haifa, Israel. Affiliated with Rambam Health Care Campus, 6 Ha'Aliya Street, Haifa, Israel, Technion (Israel \\ Institute of Technology), Technion City, Haifa, Israel. \\ ${ }^{2}$ Rambam Health Care Campus, 6 Ha'Aliya Street, Haifa, Israel. Affiliated with geriatrics department, Pardes Hana Hospital, Israel. \\ ${ }^{3}$ Neurobiology student at University of Maryland, 132 Reagents Drive, College Park, Maryland, USA. \\ ${ }^{4}$ Rambam Health Care Campus, Head, Dept. of Surgery, 6Ha'Aliya Street, Haifa, Israel and Technion, Faculty of Medicine, \\ Technion City, Haifa, Israel.
}

\begin{abstract}
Background: This study compares the long term health related quality of life (HRQOL) of conservatively treated gastric lymphoma patients to gastrectomized patients and chronic gastritis patients. The results were used to determine whether either treatment led to a better health related quality of life for patients.

Methods: The study utilized two different questionnaires, the EORTC-QLQ-30, which is used to assess quality of life in all cancer patients, and the EORTC-STO-22, which is used to assess quality of life specifically in gastric cancer patients. The participants were from a single tertiary-care oncology center. The health related quality of life of conservatively treated gastric lymphoma patients $(n=22)$ was compared with that of patients who had undergone gastrectomy $(n=34)$. Both treatment groups were also compared to a control group comprised of patients with chronic gastritis $(n=31)$.

Results: The long term health related quality of life of conservatively treated gastric lymphoma patients is as good as among patients with chronic gastritis, and better than the health related quality of life of patients who have undergone gastrectomy. The health related quality of life of the conservative treatment group is not significantly different than the control group. The health related quality of life of the surgical treatment group is significantly worse than the control group $(\mathrm{P}<<0.005)$. The gastrectomized group when compared to the conservative treatment group has more symptoms [nausea and vomiting $(p<0.04)$, sleep disturbances $(p<0.018)$, constipation $(p<0.017)$, diarrhea $(p<0.0001)$, financial difficulties $(\mathrm{p}<0.018)$, solid food dysphagia $(\mathrm{p}<0.0003)$, liquified food dysphagia $(\mathrm{p}<0.032)$, discomfort during meals $(\mathrm{p}<0.046)$, reflux (0.023), heartburn $(\mathrm{p}<0.0024)$, belching $(\mathrm{p}<0.0039)$, early satiety $(\mathrm{p}<0.047)$, and anxiety regarding hair loss $(\mathrm{p}<0.004)]$.
\end{abstract}

Conclusions: These findings indicate good health related quality of life following conservative treatment for gastric lymphoma patients.

Key words: Gastric lymphoma, gastrectomy, gastritis, quality of life, stomach

\section{Introduction}

The most common system for primary extranodal lymphoma development is the gastrointestinal system (52\%). Twenty four percent of extranodal lymphomas originate in the stomach [1]. In addition, there has been a noticeable increase in the prevalence of primary extranodal lymphoma in the last 25 years [2]. Studies have noted the drastic change in treatment for gastric lymphoma, favoring a conservative treatment method (using chemotherapy and radiotherapy), over surgery [3].

Primary Gastric Lymphoma usually develops when a person is around age 60 . The patient commonly presents with epigastric pain, early satiety, and general weakness. The diagnosis of primary gastric lymphoma requires a gastroscopic (and rarely laparoscopic) biopsy [4].

There are links between the presence of Helicobacter
Pylori (HP) and both malignancies, gastric lymphomas and gastric adenocarcinomas. HP in the stomach can cause chronic inflammation and increased development of MALT (mucosa associated lymphoid tissue) in the gastric mucosa, thus enabling lymphoma formation [5]. A 2009 study looking at the symptoms of primary gastric lymphoma, found a positive HP test in $37.5 \%$ of subjects with gastric lymphoma as well as MALT gastric lymphoma in $61.7 \%$ of subjects with gastric lymphoma [6]. HP eradication achieves low-grade, B-cell, MALT-lymphoma remission in more than $75 \%$ of patients [7], as well as in several patients with highgrade gastric lymphoma [8]. This approach is employed as first-line therapy by European oncologic guidelines [9]. In patients who fail to respond to this treatment, radiotherapy or chemotherapy is a highly successful alternative, achieving an overall remission rate of over $95 \%$ [10]. Therefore, the

C 2013 Lacther et al; licensee Herbert Publications Ltd. This is an Open Access article distributed under the terms of Creative Commons Attribution License (http://creativecommons.org/licenses/by/3.0). This permits unrestricted use, distribution, and reproduction in any medium, provided the original work is properly cited. 
surgical method is only utilized when complications occur, as a last resort [11].

In cases where antibiotic treatment does not work to treat the HP in low grade MALT lymphoma patients, the conservative treatment, specifically radiotherapy, has been used as the alternative. Psyrri et al., showed that, radiotherapy treatment with a median of dose 30 Gray, utilized after the antibiotic failed, can have a $100 \%$ complete response rate. Chemotherapy use after antibiotic treatment, although limited data is available, shows similar results to that of radiotherapy [12].

Palliative involved-field radiotherapy is appearing as another possible form of treatment for gastric lymphoma in patients with poor liver function who cannot receive chemotherapy [13]. Although palliative, the treatment has shown tumor reducing effects in Kohisa's et al., case study on a women with B-cell primary gastric lymphoma. The 73 year old presented with the disappearance of primary gastric tumors after the involved-field radiotherapy treatment and was sent home after two months [13].

There are risks and benefits to all treatments for gastric lymphoma, some more than others. Surgery offers exact histological diagnosis [14] and eliminates the small risk of gastric perforation and bleeding that chemotherapy and radiotherapy can cause. Chemotherapy and radiotherapy (conservative treatment) are important for conserving the stomach [15]. The most common form of chemotherapy is CHOP (a combined chemotherapy regimen), and radiotherapy involves focused radiation up to 40 Gray. It has been shown that the conservative treatment can cause complete remission without surgery [16].

To date, few studies have rigorously compared results on quality of life for gastric lymphoma patients when undergoing conservative vs. surgical treatments. Using the San Francisco 36-item questionnaire (SF36) and Gastrointestinal Quality of Life Index (GLQI), Fischbach et al., found superior quality of life among patients treated conservatively [17]. Local experience, confirmed by others elsewhere, noted occasions in which conservative antilymphoma therapies can yield situations with very poor gastric emptying and poor quality of life. Thus, a more specific set of HRQOL instruments, developed particularly to assess gastric problems, would be useful in assessing the HRQOL after conservative treatment.

The Gastrointestinal Quality of Life Index was published in 1995, and was meant to quantify the patient's emotional and psychological state, the patient's physical and social functioning, the symptoms, and the treatment's side effects [18]. Specific disease-oriented questionnaires are more efficient than general quality of life questionnaires [19], such as the one developed by the European Organization for Research and Therapy of Cancer (EORTC). In order to quantify HRQOL in cancer patients, the EORTC constructed a specific questionnaire: the EORTC QLQ-C30 $[\mathbf{2 0 , 2 1 ]}$. In addition, a reference data pool was constructed, as well as instructions for how to use it $[22,23]$. An appendix to the questionnaire referring specifically to gastric malignancy patients was established in 2001- the EORTC QLQ-STO22 [24]. Both EORTC's questionnaires (QLQ-C30 and QLQ-STO22) were validated in several languages including Hebrew [25] and have been used to compare HRQOL in gastrectomized patients suffering from low grade gastric carcinoma [26]. The STO-22 was specifically chosen for this study, over a general or overall gastroenterology questionnaire, so as to have the most updated and most disease- specific questionnaire, one that would relate to the very population and their specific illnesses.

The long term health related quality of life in gastric lymphoma patients treated conservatively compared to those who underwent surgery, is expected to be better due to the fact that the surgical group has a partial stomach while the conservative group has a full stomach. Therefore, we compared both treatment groups to a control group to see how the general HRQOL compared.

The aim of this study is to use the EROTC questionnaires to determine how well conservatively treated gastric lymphoma patients fare compared to gastrectomized patients based on standardized HRQOL related assessments.

\section{Materials and Methods \\ The study population}

The participants in this study were patients of Rambam Health Care Campus. The Helsinki (Institutional Review Board) committee of the hospital approved this study. Patients included both males and females who were at least 18 years old and who each gave fully informed written consent.

Patients were identified via the hospital-wide computerized database, and were approached in consecutive order to prevent bias. All conservatively treated gastric lymphoma patients and gastrectomized (partial or total) gastric carcinoma patients were at least 6 months after surgery or after starting conservative therapy for the disease, as the aim of the study was to examine long-term HRQOL after treatment.

\section{Exclusion criteria}

The only patients to be excluded from the malignancy groups were those who did not give written consent, were under age 18 , or who were within six months of their diagnosis.

Both conservatively-treated lymphoma and surgically treated gastric carcinoma patients were approached by a telephone call to inform them of the study as well as to obtain consent to send the questionnaires by mail. The questionnaire packages were sent via mail and included a questionnaire, a consent form, a letter to the primary physician informing him/her of the study, and a letter informing the patient of the study's overall goals.

The control group, consisting of chronic gastritis patients, was consecutive consenting patients referred for gastroscopy due to any symptoms, and found to have a histology- proven 
Table 1. Demography.

\begin{tabular}{|c|c|c|c|c|}
\hline & Group & $\begin{array}{l}\text { Conservative } \\
\text { treatment }(22)\end{array}$ & $\begin{array}{l}\text { Surgical } \\
\text { treatment } \\
(34)\end{array}$ & $\begin{array}{l}\text { Control } \\
(31)\end{array}$ \\
\hline $\begin{array}{l}\text { Age - average } \\
\text { (standard } \\
\text { deviation) }\end{array}$ & - & $58.2(17.1)$ & $65.6(10.9)$ & $44.6(18.6)$ \\
\hline $\begin{array}{l}\text { Male sex - } \\
\text { percentage }\end{array}$ & - & 73 & 44 & 47 \\
\hline \multirow{4}{*}{$\begin{array}{l}\text { Familial status } \\
\text { (percentage) }\end{array}$} & Bachelor & 6.6 & 4 & 33.3 \\
\hline & Married & 93.4 & 88 & 53.4 \\
\hline & Divorced & - & - & 10 \\
\hline & Widowed & - & 12 & 3.3 \\
\hline \multirow[t]{4}{*}{ Religion } & Jewish & 60 & 92 & 75 \\
\hline & Muslim & 20 & 8 & 4.2 \\
\hline & Christian & 13.3 & 4 & 12.5 \\
\hline & Druse & 6.7 & - & 8.3 \\
\hline $\begin{array}{l}\text { Approximate } \\
\text { time after } \\
\text { treatment }\end{array}$ & - & $\begin{array}{l}>6 \text { months } \\
\text { afterstarting } \\
\text { treatment }\end{array}$ & $\begin{array}{l}>6 \text { mont } \\
\text { safter surgery }\end{array}$ & $\mathrm{x}$ \\
\hline
\end{tabular}

disease of the stomach. The patients were approached before undergoing a diagnostic gastroscopy for dyspeptic symptoms. The questionnaires were completed prior to the diagnostic test in order to prevent as much bias as possible. After the gastroscopy, only patients with chronic gastritis were included in the study. Patients with ulcers or suspected malignancy did not meet the inclusion criteria and were excluded from this control group. In addition to parameters of quality of life, the study gathered data concerning demographics (age, gender, marital status and religion) and time elapsed from surgery/ last treatment.

\section{Establishing and measuring HRQOL}

Patients' health-related quality of life (HRQOL) was measured using the EORTC's Hebrew QLQ-C30 and QLQSTO22 questionnaires. Both questionnaires were validated for use in gastric malignancy patients and both were validated in Hebrew and were found culturally suitable. The questionnaires were provisioned by the EORTC. The QLQ-C30, widely used to measure HRQOL of cancer patients, includes 30 questions and checks quantitative general quality of life, various aspects of functioning (Physical, Emotional, Cognitive, Social and role functioning) and disease and treatment related symptoms. The QLQ-STO22 questionnaire was created and validated in 2001 for evaluating HRQOL of gastric malignancy patients. The questionnaire consists of 22 questions measuring frequency or intensity of gastric malignancy related symptoms.

\section{Statistical analyses}

The QLQ-30 and STO-22 results of each treatment group were compared to the control group as well as to each other, to assess the long term HRQOL of each group. The patients' data was quantified and statistically analyzed according to the EORTC's scoring manual. When interpreting the questionnaires, a higher score in the general $\mathrm{HRQOL}$ indicates better HRQOL. A higher score in the functional scales indicates better functional status. A higher symptoms score indicates higher symptom frequency or higher symptom's intensity. After calculating the average and standard deviations for each item, the group scores were compared using a t-test. The medical statistician of the hospital assisted in all analyses of data.

\section{Results}

The data collected from the patients was gathered for 4 consecutive years. Twenty two patients enrolled in the conservative treatment group (chemotherapy and/or radiation treatment for gastric lymphoma), 34 patients in the surgical group (gastrectomy due to gastric cancer), and 31 patients in the control group (chronic gastritis). All of the subjects answered all questions in both questionnaires.

The average age was not significantly different in the conservative and surgical treatment groups, but both were significantly older than the control group (Table 1). Gender was not found to be significantly different between the groups. Familial status was not significantly different between both treatment groups, but both differed significantly from the control group, which had the lowest married percentages of the three groups. There were borderline statistically significant differences regarding religious faith between the three groups (Table 1).

The pathology in the surgical group was gastric adenocarcinoma, including the pathological subclass of signet ring carcinoma, found in $10.5 \%$ of the patients. The conservative treatment group consisted of patients who were suffering from MALT lymphoma and who received chemotherapy treatment, most commonly CHOP, or radiotherapy up to 40 Gray.

In the surgical group, the average time from surgery to data collection was 2.26 years (standard deviation 1.43 years). In the conservative group, the average time from last treatment to data collection was 2.12 years (standard deviation 1.12 years). There was no statistically significant difference in this time from diagnosis between the groups $(p<0.412)$.

When comparing the QLQ-30 results in the conservative treatment and control groups, there was no significant difference in general HRQOL or in functional scales (Table 2). Even so, the conservative treatment group suffered less from pain $(p<0.0073)$, and constipation $(p<0.048)$. The control group had no advantages over the conservative treatment groups in any of the analyses.

Comparing the conservative treatment group's STO-22 results to those of the control group did not show any symptomatic advantage in the control group (Table 3 ). However, the conservative treatment group reported less heartburn $(p<0.025)$, and did not have any concern regarding 
Table 2. Comparing the QLQ-30 results of the conservative treatment group to the control group.

\begin{tabular}{llllll}
\hline & & & & \multicolumn{3}{c}{$\begin{array}{l}\text { Control group } \\
\text { group }\end{array}$} \\
\hline & p-value & Average & SD & Average & SD \\
Global Health Status QL2 & 0.05562 & 56.99 & 21.95 & 68.18 & 19.35 \\
Physical functioning PF2 & 0.62334 & 76.34 & 26.21 & 73.03 & 22.39 \\
Role functioning RF2 & 0.52449 & 77.42 & 24.17 & 73.48 & 20.35 \\
Emotional functioning EF & 0.91117 & 70.70 & 26.52 & 71.59 & 29.84 \\
Cognitive functioning CF & 0.29113 & 84.95 & 16.30 & 78.03 & 26.92 \\
Social functioning SF & 0.40587 & 82.80 & 26.35 & 75.76 & 32.42 \\
Fatigue FA & 0.67849 & 44.44 & 26.91 & 40.91 & 32.60 \\
Nausea and vomiting NV & 0.18986 & 21.51 & 21.60 & 14.39 & 17.29 \\
Pain PA & 0.00727 & 45.70 & 31.32 & 22.73 & 27.96 \\
Dyspnoea DY & 0.53639 & 17.20 & 27.04 & 22.73 & 34.71 \\
Insomnia SL & 0.55079 & 24.73 & 32.17 & 19.70 & 28.47 \\
Appetite loss AP & 0.39898 & 26.88 & 32.68 & 19.70 & 28.47 \\
Constipation CO & 0.04755 & 18.28 & 27.00 & 6.06 & 16.70 \\
Diarrhea DI & 0.39858 & 11.83 & 20.27 & 18.18 & 30.39 \\
Financial difficulties FI & 0.55079 & 24.73 & 32.17 & 19.70 & 28.47 \\
\hline & & & & &
\end{tabular}

Table 3. Comparing the STO-22 results of the conservative treatment group to the control group.

\begin{tabular}{llllll}
\hline & & & & \multicolumn{3}{l}{ Control group } & $\begin{array}{l}\text { Conservative } \\
\text { treatment } \\
\text { group }\end{array}$ \\
\hline Solids dysphagia & p-value & Average & SD & Average & SD \\
Soft food dysphagia & 0.88366 & 12.90 & 18.61 & 12.12 & 19.37 \\
Liquid dysphagia & 0.15948 & 5.38 & 12.46 & 1.52 & 7.11 \\
Eating discomfort & 0.90779 & 5.38 & 19.43 & 6.06 & 22.15 \\
Epigastric pain & 0.16915 & 29.03 & 29.49 & 18.18 & 26.68 \\
Epigastric discomfort & 0.39010 & 41.94 & 35.45 & 33.33 & 35.63 \\
Bloating & 0.76303 & 40.86 & 36.22 & 37.88 & 34.57 \\
Reflux & 0.83699 & 35.48 & 33.26 & 33.33 & 39.84 \\
Heartburn & 0.35558 & 26.88 & 29.08 & 19.70 & 26.55 \\
Belching & 0.02493 & 33.33 & 35.49 & 13.64 & 26.55 \\
Early satiety & 0.68805 & 12.90 & 18.61 & 10.61 & 21.54 \\
Trouble enjoying meals & 0.13142 & 20.43 & 31.83 & 34.85 & 34.85 \\
Long sittings & 0.61417 & 26.88 & 32.68 & 31.82 & 36.34 \\
Dry mouth & 0.40413 & 23.66 & 28.79 & 16.67 & 30.43 \\
Different taste & 0.96973 & 39.78 & 32.68 & 39.39 & 39.36 \\
Public eating anxiety & 0.20082 & 7.53 & 14.17 & 15.15 & 24.62 \\
Thoughts about the & 0.44595 & 6.45 & 20.04 & 12.12 & 30.07 \\
gastric illnes & 0.98786 & 44.09 & 29.04 & 43.94 & 37.64 \\
Underweight anxiety & & & & & \\
Unattractiveness & 0.62749 & 22.58 & 34.84 & 18.18 & 30.39 \\
Health anxiety & 0.44786 & 15.05 & 27.00 & 21.21 & 30.07 \\
Loss of hair & 0.84012 & 47.31 & 29.53 & 45.45 & 34.95 \\
Worried about hair loss & 0.67734 & 17.20 & 25.63 & 21.21 & 39.23 \\
\hline & 0.00027 & 51.52 & 31.14 & 00.00 & 00.00 \\
\hline & & & & &
\end{tabular}

hair loss, which was significantly less than the control group $(p<0.0003)$.

When comparing the control and gastrectomy groups, the control group had a significantly better overall HRQOL
Table 4. Comparing the QLQ-30 results of the surgical treatment group to the control group.

\begin{tabular}{llllll}
\hline & & & Control group & $\begin{array}{l}\text { Surgical } \\
\text { treatment } \\
\text { group }\end{array}$ \\
\hline Global Health Status QL2 & 0.922 & 56.99 & 21.95 & 57.6 & 27.93 \\
Physical functioning PF2 & 0.249 & 76.34 & 26.21 & 69.41 & 21.22 \\
Role functioning RF2 & 0.0244 & 77.42 & 24.17 & 62.25 & 28.81 \\
Emotional functioning EF & 0.3968 & 70.7 & 26.52 & 64.22 & 33.49 \\
Cognitive functioning CF & 0.00249 & 84.95 & 16.3 & 65.2 & 31.88 \\
Social functioning SF & 0.04014 & 82.8 & 26.35 & 66.18 & 37.04 \\
Fatigue FA & 0.12143 & 44.44 & 26.91 & 55.23 & 28.49 \\
Nausea and vomiting NV & 0.32879 & 21.51 & 21.6 & 27.94 & 30.63 \\
Pain PA & 0.1696 & 45.7 & 31.32 & 34.8 & 31.88 \\
Dyspnoea DY & 0.45834 & 17.2 & 27.04 & 12.75 & 20.13 \\
Insomnia SL & 0.05889 & 24.73 & 32.17 & 41.18 & 36.75 \\
Appetite loss AP & 0.84006 & 26.88 & 32.68 & 28.43 & 28.58 \\
Constipation CO & 0.73266 & 18.28 & 27 & 20.59 & 27.23 \\
Diarrhea DI & 0.000007 & 11.83 & 20.27 & 51.96 & 41.19 \\
Financial difficulties FI & 0.05889 & 24.73 & 32.17 & 41.18 & 36.75 \\
\hline
\end{tabular}

Table 5. Comparing the STO-22 results of the surgical treatment group to the Control.

\begin{tabular}{|c|c|c|c|c|c|}
\hline & & \multicolumn{2}{|c|}{ Control Group } & \multicolumn{2}{|c|}{$\begin{array}{l}\text { Surgical } \\
\text { treatment } \\
\text { group }\end{array}$} \\
\hline & p-value & Average & SD & Average & SD \\
\hline Solids dysphagia & 0.00018 & 12.9 & 18.61 & 41.18 & 35.82 \\
\hline Soft food dysphagia & 0.35356 & 5.38 & 12.46 & 8.82 & 17.03 \\
\hline Liquid dysphagia & 0.07377 & 5.38 & 19.43 & 16.67 & 29.87 \\
\hline Eating discomfort & 0.44236 & 29.03 & 29.49 & 35.29 & 35.71 \\
\hline Epigastric pain & 0.58693 & 41.94 & 35.45 & 37.25 & 33.6 \\
\hline Epigastric discomfort & 0.6279 & 40.86 & 36.22 & 45.1 & 33.72 \\
\hline Bloating & 0.57708 & 35.48 & 33.26 & 40.2 & 34.6 \\
\hline Reflux & 0.12762 & 26.88 & 29.08 & 39.22 & 35.27 \\
\hline Heartburn & 0.43906 & 33.33 & 35.49 & 40.2 & 35.56 \\
\hline Belching & 0.0045 & 12.9 & 18.61 & 34.31 & 37.14 \\
\hline Early satiation & 0.000166 & 20.43 & 31.83 & 54.9 & 37.5 \\
\hline Trouble enjoying meals & 0.11959 & 26.88 & 32.68 & 41.18 & 40.25 \\
\hline Long sittings & 0.40738 & 23.66 & 28.79 & 30.39 & 36.11 \\
\hline Dry mouth & 0.36788 & 39.78 & 32.68 & 32.35 & 33.32 \\
\hline Different taste & 0.04516 & 7.53 & 14.17 & 20.59 & 33.85 \\
\hline Public eating anxiety & 0.06514 & 6.45 & 20.04 & 19.61 & 34.93 \\
\hline $\begin{array}{l}\text { Thoughts about the } \\
\text { gastricillness }\end{array}$ & 0.08463 & 44.09 & 29.04 & 58.82 & 38.54 \\
\hline Underweight anxiety & 0.10294 & 22.58 & 34.84 & 32.35 & 41.43 \\
\hline Unattractiveness & 0.09395 & 15.05 & 27 & 27.45 & 33.3 \\
\hline Health anxiety & 0.09539 & 47.31 & 29.53 & 60.78 & 34.3 \\
\hline Loss of hair & 0.07081 & 17.2 & 25.63 & 32.35 & 39.77 \\
\hline Worried about hair loss & 0.02241 & 51.52 & 31.14 & 31.37 & 38.13 \\
\hline
\end{tabular}

according to both the QLQ-30 ( $p<.04)$ (Table 4) and STO-22 ( $p<<.005$ ) (Table 5). According to the QLQ-30 results, the surgical group compared to the control group had significantly worse role functioning $(p<0.02)$, worse cognitive 
Lachter et al. Journal of Cancer Therapeutics \& Research 2013, http://www.hoajonline.com/journals/pdf/2049-7962-2-6.pdf

Table 6. Comparing the QLQ-30 results in the treatment groups.

\begin{tabular}{llllll}
\hline & & $\begin{array}{l}\text { Conservative } \\
\text { treatment } \\
\text { group }\end{array}$ & $\begin{array}{l}\text { Surgical } \\
\text { treatment } \\
\text { group }\end{array}$ \\
\hline & p-Value & Average & SD & Average & SD \\
Global Health Status QL2 & 0.09994 & 68.18 & 19.35 & 57.60 & 27.93 \\
Physical functioning PF2 & 0.54979 & 73.03 & 22.39 & 69.41 & 21.22 \\
Role functioning RF2 & 0.09349 & 73.48 & 20.35 & 62.25 & 28.81 \\
Emotional functioning EF & 0.39379 & 71.59 & 29.84 & 64.22 & 33.49 \\
Cognitive functioning CF & 0.11167 & 78.03 & 26.92 & 65.20 & 31.88 \\
Social functioning SF & 0.31242 & 75.76 & 32.42 & 66.18 & 37.04 \\
Fatigue FA & 0.09957 & 40.91 & 32.60 & 55.23 & 28.49 \\
Nausea and vomiting NV & 0.03946 & 14.39 & 17.29 & 27.94 & 30.63 \\
Pain PA & 0.14181 & 22.73 & 27.96 & 34.80 & 31.88 \\
Dyspnoea DY & 0.23099 & 22.73 & 34.71 & 12.75 & 20.13 \\
Insomnia SL & 0.01747 & 19.70 & 28.47 & 41.18 & 36.75 \\
Appetite loss AP & 0.26884 & 19.70 & 28.47 & 28.43 & 28.58 \\
Constipation CO & 0.01656 & 6.06 & 16.70 & 20.59 & 27.23 \\
Diarrhea DI & 0.00088 & 18.18 & 30.39 & 51.96 & 41.19 \\
Financial difficultiesFI & 0.01747 & 19.70 & 28.47 & 41.18 & 36.75 \\
\hline & & & & &
\end{tabular}

Table 7. Comparing the STO-22 results in the treatment groups.

\begin{tabular}{|c|c|c|c|c|c|}
\hline & & $\begin{array}{l}\text { Surgical } \\
\text { treatmer }\end{array}$ & & $\begin{array}{l}\text { Conserv } \\
\text { treatmei }\end{array}$ & \\
\hline & $\mathrm{p}$-value & Average & SD & Average & SD \\
\hline Solids dysphagia & 0.00025 & 41.18 & 35.82 & 12.12 & 19.37 \\
\hline Soft food dysphagia & 0.03115 & 8.82 & 17.03 & 1.52 & 7.11 \\
\hline Liquid dysphagia & 0.13390 & 16.67 & 29.87 & 6.06 & 22.15 \\
\hline Eating discomfort & 0.04563 & 35.29 & 35.71 & 18.18 & 26.68 \\
\hline Epigastric pain & 0.68292 & 37.25 & 33.60 & 33.33 & 35.63 \\
\hline Epigastric discomfort & 0.44505 & 45.10 & 33.72 & 37.88 & 34.57 \\
\hline Bloating & 0.51153 & 40.20 & 34.60 & 33.33 & 39.84 \\
\hline Reflux & 0.02221 & 39.22 & 35.27 & 19.70 & 26.55 \\
\hline Heartburn & 0.00238 & 40.20 & 35.56 & 13.64 & 26.55 \\
\hline Belching & 0.00388 & 34.31 & 37.14 & 10.61 & 21.54 \\
\hline Early satiation & 0.04688 & 54.90 & 37.50 & 34.85 & 34.85 \\
\hline Trouble enjoying meals & 0.37159 & 41.18 & 40.25 & 31.82 & 36.34 \\
\hline Long sittings & 0.13222 & 30.39 & 36.11 & 16.67 & 30.43 \\
\hline Dry mouth & 0.49199 & 32.35 & 33.32 & 39.39 & 39.36 \\
\hline Different taste & 0.49027 & 20.59 & 33.85 & 15.15 & 24.62 \\
\hline Public eating anxiety & 0.39762 & 19.61 & 34.93 & 12.12 & 30.07 \\
\hline $\begin{array}{l}\text { Thoughts about the } \\
\text { gastric illness }\end{array}$ & 0.15902 & 58.82 & 38.54 & 43.94 & 37.64 \\
\hline Underweight anxiety & 0.14644 & 32.35 & 41.43 & 18.18 & 30.39 \\
\hline Unattractiveness & 0.47098 & 27.45 & 33.30 & 21.21 & 30.07 \\
\hline Health anxiety & 0.11347 & 60.78 & 34.30 & 45.45 & 34.95 \\
\hline Loss of hair & 0.30741 & 32.35 & 39.77 & 21.21 & 39.23 \\
\hline Worried about hair loss & 0.00372 & 31.37 & 38.13 & 0.00 & 0.00 \\
\hline
\end{tabular}

functioning $(p<0.002)$, worse social functioning $(p<0.04)$ and more diarrhea $(p<0.000007)$. The STO-22 results showed that the surgical group, compared to the control group, had more solids dysphagia $(p<0.00018)$, more belching $(p<0.0045)$, more early satiation ( $p<.00017)$, more differences in taste $(p<.045)$ and less worries about hair loss $(p<.022)$.

When comparing the QLQ-30 results of the conservative and surgical treatment groups, there was no significant difference in general $\mathrm{HRQOL}$ or in functional scales (Table 6). The surgical treatment group had more nausea $(p<0.039)$, sleep disturbances $(p<0.017)$, constipation $(p<0.017)$, diarrhea $(p<0.001)$, and financial difficulties $(p<0.017)$.

When comparing the two treatment groups' STO-22 results, the surgical treatment group had more gastric symptoms than the conservative treatment group (Table 7). The symptoms that were reported more frequently by the surgical group were: solids dysphagia $(p<0.0003)$, soft food dysphagia ( $p<0.031)$, eating discomfort $(p<0.046)$, reflux $(p<0.022)$, heartburn $(p<0.0024)$, belching $(p<0.0039)$, early satiety $(p<0.047)$, and concerns due to hair loss $(p<0.0037)$.

\section{Discussion}

Several patients who have had conservative treatment for gastric lymphoma had complaints regarding the gastrointestinal system, especially early satiation and lack of gastric emptying. Thus, this work set out to examine whether the conservative treatment for gastric lymphoma had any advantages over gastrectomized patients symptom-wise, especially since the existing literature does not show a prognostic survival advantage to either of the treatments among gastric lymphoma patients [27].

It is important to mention that the surgical option is still widely used and is a valid treatment, especially due to the possible complications of the conservative treatment (ulcerations, bleeding, recurrence of the gastric lymphoma, etc.). However, certain aspects of quality of life after a gastrectomy have been known to diminish-increased nausea and vomiting, financial difficulties, reflux, eating restrictions and increased issues with body image [28].

The primary endpoint of this research was to compare the HRQOL of gastric lymphoma patients who received conservative treatment to the HRQOL of patients who received a gastrectomy due to gastric malignancy using a more specific questionnaire (EROTC STO-22). Ideally, a comparison might be made between gastric lymphoma patients who were treated conservatively (chemotherapy with or without radiotherapy) versus surgically (gastrectomy). Since the trend to choose conservative treatment has been prevalent for over a decade in the tertiary medical center in which this research was conducted, there were no surviving gastric lymphoma patients who had undergone a gastrectomy. Thus, this study compares the HRQOL of a conservative treatment group to a group of patients who had undergone gastrectomy for a gastric malignancy, 
relying on the premise that the $\mathrm{HRQOL}$ is derived mostly from the operation itself (gastrectomy), rather than the underlying gastric lymphoma.

The two treatment groups were compared to a relevant control group. We established a control group consisting of patients with benign chronic inflammatory upper gastrointestinal disease (non ulcerative chronic gastritis). We chose this as a control group because it represents the $\mathrm{HRQOL}$ of patients with a much more trivial disease than gastric lymphoma and gastric carcinoma, yet from the same origin of complication, the stomach. Many studies do not choose to use a group of patients with a trivial disease as their control, however a trivial disease can prove to be a more accurate comparison group when looking at $\mathrm{HRQOL}$ of patients with gastrointestinal diseases, rather than comparing them to normal healthy patients.

The findings show that the global $\mathrm{HRQOL}$ is not statistically significantly different between the conservative and control group or between the two treatment groups. The HRQOL of the surgically treated group was statistically significantly less than the control group. In addition, compared to the surgically treated group, the conservative treatment group has less general malignancy related symptoms (sleep disturbances, constipation, diarrhea, nausea and vomiting, and financial difficulties), and less gastric-malignancy related symptoms (solids dysphagia, soft food dysphagia, liquid dysphagia, eating discomfort, reflux, heartburn, belching, and early satiety). The surgical treatment group had many more occurring symptoms than the control group (solids dysphagia, belching, early satiation, differences in taste and worries about hair loss). The control group actually had more symptoms than the conservative group (pain, constipation, heartburn and hair loss).

The conservative treatment group is more comparable to the control group than the surgical treatment group as well as presents with less symptoms than both the surgical treatment group and control group. This suggests that the conservative treatment group offers an overall better quality of life than the surgical treatment group, and even presents with less symptoms than patients with a trivial disease gastritis.

Previous studies have shown similar findings when comparing conservative verse surgical treatment for gastric lymphoma. A 2011 study comparing the two types of treatments using the Gastro Intestinal Quality of Life Index (GLQI) found that, after treatment for gastric lymphoma, "Posttherapeutic quality of life was generally high with a significant advantage for patients treated conservatively compared to those who underwent surgery" [17]. Showing a more favorable outcome of quality of life after chemotherapy compared to after a gastrectomy for gastric lymphoma patients. The present study used the more specific STO-22 of the EORTC, rather than the more general GLQI. In using the EORTC surveys, the current project has at least a theoretical advantage in that it applies a tool designed specifically for evaluation of stomach and not general gastrointestinal QOL issues.

There was a statistically significant difference between the control group and the treatment groups for fear of hair loss. It was surprising to find that both treatment groups reported less fear of hair loss than the control group, who did not have any malignant comorbidity. In addition to these findings, the conservative treatment group unanimously reported no fear of hair loss. Even conservative treatment patients who reported actual hair loss did not report any fear of hair loss. It is reasonable to assume that many people with malignancies of any kind have more important and existential concerns than hair loss. Another support to this finding can be found in higher prevalence of anxietyrelated symptoms and even full blown post-traumatic stress disorder in lymphoma survivors, years after completing the therapy for the lymphoma [29]. The validity of these findings is even stronger taking into consideration that all patients completed each questionnaire entirely without missing a single question.

\section{Limitations}

As mentioned in the discussion section above, the surgical treatment group did not have the same underlying malignancy as the conservative treatment group.

One study from the Cleveland Clinic mentions, for example, that "post gastrectomy syndrome" is one of the side affects of a gastrectomy and is seen in patients who have many different reasons for receiving the surgery in the first place [30]. The symptoms and side effects that lower patient's HRQOL after a gastrectomy are assumed to be similar even if the reason for the gastrectomy is different; the symptoms are most likely caused by the procedure rather than the original disease. The study assumed that patients were past their disease in both cases and now dealt only with side effects from their treatment [30].

Another limitation is that research is cross-sectional rather than prospective. An improved version might be to prospectively collect similar data, if such were still possible.

In addition, the ages of the patients were variable between the three groups included in the study. This difference could have had a possible effect on the different QOL scores. However, it was not found that younger age correlated with better QOL within any of the groups, thus it might be reasonably hypothesized that age was not a decisive variable.

\section{Conclusions}

Comparing the results of the health related quality of life questionnaires of the EORTC (the QLQ-30 and STO-22), revealed that gastric lymphoma patients, who were treated conservatively, were more comparable to the control group, had lower general malignancy-related symptoms and less organ-specific symptoms, than those who underwent a gastrectomy for carcinomas. In relation to health related quality of life according to both questionnaires, there were 
no significant advantages of the surgical treatment group over the conservative treatment group and no advantages of the control group of chronic gastritis patients over the conservative treatment group.

These findings support earlier data that compared gastric lymphoma patients, a year after completing conservative treatment, to the general population, and found that the differences in HRQOL were negligible [31]. The results also support the findings of a 2011 study that concluded, "long-term outcome of patients with gastric lymphoma is excellent irrespective of the lymphoma type and the treatment approach. Considering quality of life a conservative therapeutic strategy should be favored" [17].

The present research findings support the impression that the HRQOL of conservatively treated gastric lymphoma patients is favorable and in several ways better than that of patients with common chronic gastritis as well as patients who have had a gastrectomy, and should therefore be the favorable form of treatment when available.

\section{Competing interests}

The authors declare that they have no competing interests.

Publication history

Received: 10-Dec-2012 Revised: 29-Dec-2012

Re-Revised: 15-Jan-2013 Accepted: 23-Jan-2013

Published: 29-Jan-2013

\section{References}

1. Radaszkiewicz T, Dragosics B and Bauer P: Gastrointestinal malignant lymphomas of the mucosa-associated lymphoid tissue: factors relevant to prognosis. Gastroenterology 1992, 102:1628-38. | Article I PubMed

2. Fischbach W, Dragosics B, Kolve-Goebeler ME, Ohmann C, Greiner A, Yang Q, Bohm S, Verreet P, Horstmann O, Busch M: Primary gastric B-cell lymphoma: results of a prospective multicenter study. The German-Austrian Gastrointestinal Lymphoma Study Group. Gastroenterology 2000, 119:1191-202. | Article | PubMed

3. Fischbach W: Long-term follow-up of gastric lymphoma after stomach conserving treatment. Best Pract Res Clin Gastroenterol 2010, 24:71-7. | Article | PubMed

4. Mayer, J. Gastrointestinal tract cancer. In: Braunwald E, Hauser SL, Fauci AS, Longo DL, Kasper DL, Jameson JL: Harrison's principles of internal medicine (15th edition). New York: McGraw-Hill, 2001: 581

5. Muller AF, Maloney A, Jenkins D, Dowling F, Smith P, Bessell EM and Toghill PJ: Primary gastric lymphoma in clinical practice 1973-1992. Gut 1995, 36:679-83. | PDF | PubMed Abstract | PubMed Full Text

6. Feng L, Zhang G, Hu Z, Zou Y, Chen F and Tang L: Diagnosis and treatment of 81 patients with primary gastrointestinal lymphoma. Zhong Nan Da Xue Xue Bao Yi Xue Ban 2009, 34:582-8. | PDF | PubMed

7. Zullo A, Hassan C, Cristofari F, Andriani A, De Francesco V, lerardi E, Tomao S, Stolte M, Morini S and Vaira D: Effects of Helicobacter pylori eradication on early stage gastric mucosa-associated lymphoid tissue lymphoma. Clin Gastroenterol Hepatol 2010, 8:105-10. | Article | PubMed

8. Cavanna L, Pagani R, Seghini P, Zangrandi A and Paties C: High grade B-cell gastric lymphoma with complete pathologic remission after eradication of Helicobacter pylori infection: report of a case and review of the literature. World J Surg Oncol 2008, 6:35. | Article | PubMed Abstract I PubMed Full Text
9. Zucca E and Dreyling M: Gastric marginal zone lymphoma of MALT type: ESMO clinical recommendations for diagnosis, treatment and follow-up. Ann Oncol 2008, 19 Suppl 2:ii70-1. | Article | PubMed

10. Zullo A, Hassan C, Andriani A, Cristofari F, Bassanelli C, Spinelli GP, Tomao S and Morini S: Treatment of low-grade gastric MALTlymphoma unresponsive to Helicobacter pylori therapy: a pooleddata analysis. Med Oncol 2010, 27:291-5. | Article I PubMed

11. Zullo A, Hassan C, Cristofari F, Perri F and Morini S: Gastric low-grade mucosal-associated lymphoid tissue-lymphoma: Helicobacter pylori and beyond. World J Gastrointest Oncol 2010, 2:181-6. | Article | PubMed Abstract I PubMed Full Text

12. Psyrri A, Papageorgiou $S$ and Economopoulos $\mathrm{T}$ : Primary extranodal lymphomas of stomach: clinical presentation, diagnostic pitfalls and management. Ann Oncol 2008, 19:1992-9. | Article | PubMed Abstract | PubMed Full Text

13. Kohisa J, Kamimura K, Iwanaga A, Shioji K, Kawai H, Suda T, Suzuki K, Sakurada J, Naito M, Aoyagi Y: Efficient palliative involved-field radiotherapy on highly progressivediffuse large B-cell primary gastric lymphoma with liver cirrhosis. Clin J Gastroenterol 2012, 5:164-169. | Article

14. Kodera Y, Nakamura S, Yamamura Y, Shimizu Y, Torii A, Hirai T, Yasui K, Morimoto T and Kato T: Primary gastric B cell lymphoma: audit of 82 cases treated with surgery and classified according to the concept of mucosa-associated lymphoid tissue lymphoma. World I Surg 2000, 24:857-62. | Article | PubMed

15. Maor MH, Velasquez WS, Fuller LM and Silvermintz KB: Stomach conservation in stages IE and IIE gastric non-Hodgkin's lymphoma. $J$ Clin Oncol 1990, 8:266-71. | Article | PubMed

16. Burgers JM, Taal BG, van Heerde $P$, Somers $R$, den Hartog Jager FC and Hart AA: Treatment results of primary stage I and II nonHodgkin's lymphoma of the stomach. Radiother Oncol 1988, 11:31926. | Article | PubMed

17. Fischbach W, Schramm S and Goebeler E: Outcome and quality of life favour a conservative treatment of patients with primary gastric lymphoma. Z Gastroenterol 2011, 49:430-5. | Article | PubMed

18. Eypasch E, Williams JI, Wood-Dauphinee S, Ure BM, Schmulling C, Neugebauer $E$ and Troidl H: Gastrointestinal Quality of Life Index: development, validation and application of a new instrument. $\mathrm{Br} J$ Surg 1995, 82:216-22. I Article | PubMed

19. Kusche J, Vestweber K, Troidl H: Quality of life after total gastrectomy for stomach cancer. Scand. J. Gastroenterol 1987, 22: 96-101. | Article

20. Aaronson NK, Ahmedzai S, Bergman B, Bullinger M, Cull A, Duez NJ, Filiberti A, Flechtner H, Fleishman SB, de Haes JC and et al.: The European Organization for Research and Treatment of Cancer QLQ-C30: a quality-of-life instrument for use in international clinical trials in oncology. J Natl Cancer Inst 1993, 85:365-76. | Article I PubMed

21. Fayers PM: Interpreting quality of life data: population-based reference data for the EORTC QLQ-C30. Eur J Cancer 2001, 37:1331-4. | Article | PubMed

22. Schwarz R and Hinz A: Reference data for the quality of life questionnaire EORTC QLQ-C30 in the general German population. Eur J Cancer 2001, 37:1345-51. | Article I PubMed

23. Hjermstad MJ, Fayers PM, Bjordal K and Kaasa S: Using reference data on quality of life--the importance of adjusting for age and gender, exemplified by the EORTC QLQ-C30 (+3). Eur J Cancer 1998, 34:1381-9. | Article | PubMed

24. Vickery CW, Blazeby JM, Conroy T, Arraras J, Sezer O, Koller M, Rosemeyer D, Johnson CD and Alderson D: Development of an EORTC disease-specific quality of life module for use in patients with gastric cancer. Eur J Cancer 2001, 37:966-71. | Article | PubMed

25. Huang CC, Lien HH, Sung YC, Liu HT and Chie WC: Quality of life of patients with gastric cancer in Taiwan: validation and clinical application of the Taiwan Chinese version of the EORTC QLQ-C30 and EORTC QLQ-STO22. Psychooncology 2007, 16:945-9. | Article 
I PubMed

26. Huang CC, Lien HH, Wang PC, Yang JC, Cheng CY and Huang CS: Quality of life in disease-free gastric adenocarcinoma survivors: impacts of clinical stages and reconstructive surgical procedures. Dig Surg 2007, 24:59-65. | Article | PubMed

27. Binn $M$, Ruskone-Fourmestraux A, Lepage E, Haioun C, Delmer A, Aegerter P, Lavergne A, Guettier C and Delchier JC: Surgical resection plus chemotherapy versus chemotherapy alone: comparison of two strategies to treat diffuse large B-cell gastric lymphoma. Ann Oncol 2003, 14:1751-7. | Article | PubMed

28. Lee SS, Chung HY and Yu W: Quality of life of long-term survivors after a distal subtotal gastrectomy. Cancer Res Treat 2010, 42:1304. | Article | PubMed Abstract | PubMed Full Text

29. Geffen DB, Blaustein A, Amir MC and Cohen Y: Post-traumatic stress disorder and quality of life in long-term survivors of Hodgkin's disease and non-Hodgkin's lymphoma in Israel. Leuk Lymphoma 2003, 44:1925-9. | Article | PubMed

30. Post gastrectomy syndrome overview. Cleveland Clinic 2012. | Website

31. Kim WS, Park YH, Lee SH, Ryoo BY, Yang SH, Lee SS, Kim MS, Kim K, Park KW, Im do H, Kang JH, Lee J, Ko YH, Ahn YC, Lim do H, Park $\mathrm{K}$ and Bang SM: Quality of life one year after chemoradiotherapy for localized primary gastric diffuse large B-cell lymphoma. Med Oncol 2008, 25:447-50. | Article | PubMed

\section{Citation:}

Lachter J, Shahory R, Molin N and Kluger Y: Long term quality of life in conservatively treated gastric lymphoma patients versus gastrectomized patients and gastritis patients. journal of Cancer Therapeutics and Research 2013, 2:6.

http://dx.doi.org/10.7243/2049-7962-2-6 